\title{
水利水电工程中的灌浆施工技术探讨
}

\author{
蒋磊磊 \\ 长江三峡技术经济发展有限公司 \\ DOI:10.32629/hwr.v3i11.2494
}

[ 摘 要] 在水利水电工程中,灌浆施工技术以及自身所具备的众多特点得到广泛应用。基于此,文章以水利水电工程中较具代表性的水电站为 例, 对灌浆施工技术中的帷幕灌浆和固结灌浆工艺及实施要点进行论述。为确保灌浆施工的整体质量,作业人员应了解并掌握其中的关键技术, 并做好质量检查工作,这样才能使灌浆施工按质、按量、按时完成。

[关键词] 水利水电; 灌浆; 施工技术

\section{1 工程概况}

某水利水电工程位于XX省境内, 是一座以发电为主的水电站, 总装机 容量为 $3200 \mathrm{~kW}$ 。水库总库容量约为 360 万 $\mathrm{m}^{3}$, 正常蓄水位 $600 \mathrm{~m}$ 。为有效防止 该水电站出现渗漏的情况, 决定采用帷幕灌浆施工技术, 同时, 采用固结灌 浆增强坝基的整体性, 整个灌浆工程贯穿于该水电站上游帷幕线, 沿线较 长, 点多面广, 工程量相对较大。为确保帷幕灌浆和固结灌浆施工的整体质 量, 作业人员应当对相关的施工技术要点加以了解和掌握。

\section{2 水利水电工程中的灌浆施工技术}

在本工程中, 灌浆施工采用的是帷幕灌浆和固结灌浆工艺, 为使灌浆 质量得到有效保障, 作业人员应掌握相关的施工技术要点, 具体如下:

2. 1 帷幕灌浆施工技术要点

2.1. 1 钻孔

在帷幕灌浆施工中, 钻孔是较为重要的环节之一, 具体的实施要点如下:

(1)作业人员应当根据设计图纸中给出的位置在施工现场对孔位进行 布设, 要求现场布置的孔位与设计图纸中给出的孔位偏差不得超过 $10 \mathrm{~cm}$, 若是存在特殊情况, 需要对现场孔位进行调整时, 则应报监理工程师批准 后方可实施, 并对现场实际孔位进行记录。

(2)在本工程中, 帷幕灌浆孔采用回转式地质钻机进行钻设, 位于覆盖 层内的钻孔, 可以通过跟管钻进或是泥浆护壁的方法成孔, 当覆盖层内的 钻孔施工完毕后, 应及时在孔内下入保护管。

(3)在钻孔的过程中, 应当对孔向和孔斜进行有效控制, 要确保钻机平 稳、牢固, 使用罗盘对钻机的立轴角度进行测量, 使其与设计孔向相符; 为 保证防渗帷幕的连续性, 可以采用测斜仪对帷幕灌浆孔进行孔段侧斜, 孔 底偏差不得超过规范要求, 如果偏斜值超限, 应当及时采取相应的措施进 行纠偏, 若是纠偏无效, 则应在距离原孔位 $20 \mathrm{~cm}$ 左右的位置处, 重新开设新 的孔位。

(4)对帷幕灌浆孔进行钻设时, 可按如下标准对钻孔深度进行控制：依 据设计图纸中给出的底线高程进行控制, 确保实际孔深与设计孔深之间的 误差在 $20 \mathrm{~cm}$ 以内, 终孔后, 孔内残渣的厚度应当小于 $20 \mathrm{~cm}$ 。如果施工过程中, 出现如下情况导致无法继续钻进: 塌孔、卡钻、漏水等, 应先灌浆, 再钻孔, 若是出现掉钻的现象, 则应当停钻, 并及时查明原因, 待处理后, 方可恢复 钻进。

(5)在钻孔的过程中, 作业人员应当对孔内的特殊情况进行详细记录, 如涌水、掉块、塌孔、掉钻等等, 并在钻孔完毕后, 及时进行冲洗, 可采用 风水联合的方法清洗钻孔, 也可以利用导管通入水流, 从孔底向孔外冲洗。 对钻孔进行冲洗时, 可将冲洗压力控制在灌浆压力的 $80 \%$ 左右, 不超过 $1 \mathrm{MPa}$, 风压控制在灌浆压力的 $50 \%$ 左右。正式灌浆前, 应当进行压水试验, 本工程 中采用的是单点法进行压水试验, 当试验合格后, 便可开始灌浆。

\subsection{2灌浆}

在本工程中, 帷幕灌浆遵循逐序加密的原则进行施工, 灌浆孔共分为 两个次序进行施工, 具体的施工技术要点如下:

(1)先对混凝土与基岩的接触段进行单独灌浆, 用双管循环式栓塞卡在 基岩面以上的混凝土段内, 确保尾管与孔底之间距离在 $50 \mathrm{~cm}$ 以上, 随后便 可进行循环灌浆。当灌浆完毕后, 可用预先拌制好的水泥浆镶入孔口管, 并使其高出混凝土面 $10 \mathrm{~cm}$ 左右, 这样能够有效防止泥水等污物流入孔内。

(2)在灌浆的过程中, 应使灌浆压力尽快达到设计压力, 如果灌浆时的 注入率较大, 则应采用分级或是间歇升压的方法进行灌浆, 这样能够确保 灌浆压力与注入率相匹配; 为便于操控, 可将回浆管路上的压力表安装在 灌浆自动记录仪的附近, 应确保压力表与灌浆孔之间的管路长度不超过 $30 \mathrm{~m}$, 从而使压力表的读数能准确反映出灌浆压力。

(3)灌浆时, 作业人员应当每间隔 $15-30 \mathrm{~min}$ 左右, 对浆液密度计回浆温 度进行测量和记录, 当灌浆在最大设计压力下, 注入率低于 $1.0 \mathrm{~L} / \mathrm{min}$ 时, 持 续灌注 $30 \mathrm{~min}$, 便可停灌。若是灌浆孔在较长的时间内无法达到停灌标准, 则应报现场监理工程师, 按照批准的措施进行处理。

(4)当所有的帷幕灌浆孔全部灌注完毕, 且质检合格后, 便可进行封孔, 并在孔内浆液固结后, 将浮浆清除干净。

\subsection{3 质量检查}

在本工程中, 为确保帷幕灌浆的施工质量, 施工过程中需严格落实三 检制度。可采用压水检查, 如有必要可请第三方进行检测。帷幕灌浆检查 孔的数量应当不少于灌浆孔数的 $10 \%$, 帷幕轴线每隔 $20 \mathrm{~m}$ 左右, 应至少设置 一个检查孔。

2. 2 固结灌浆施工技术要点

2.2.1 钻孔与冲洗

在本工程中, 固结灌浆的孔间距和排距均为 $3.0 \mathrm{~m}$, 钻孔时, 按照设计孔 深一次性成孔, 采用潜孔钻进行钻孔, 为防止孔斜, 应当在施工中采取有效 的措施, 并确保孔向准确无误。当钻孔完毕后, 应当在固结灌浆前, 对钻孔 进行冲洗, 具体的施工技术要点与帷幕灌浆钻孔冲洗相同, 在此不进行累 述。对裂隙进行冲洗时, 应当注意如下事项：邻近固结灌浆孔正在灌浆或 是灌浆结束未超过 $24 \mathrm{~h}$ 时, 不得进行裂隙冲洗, 对同一个孔段进行裂隙冲洗 时应当连续进行, 如果由于特殊原因导致冲洗中断, 且 $24 \mathrm{~h}$ 内未恢复, 则应 在灌注前, 重新进行裂隙冲洗。

\subsection{2压水试验}

可在裂隙冲洗完毕的 $24 \mathrm{~h}$ 内, 采用分段的方式, 以单点法对固结灌浆孔 进行压水试验。压水试验的压力超过1.0MPa时, 应采用1.0 MPa。在压力稳 定的前提条件下, 每间隔 $5.0 \mathrm{~min}$ 对压入流量进行测读, 当连续 4 次中读数的 最大值与最小值的差小于最终值 $10 \%$, 便可结束, 并以最终值作为岩体透水 


\title{
刍议结构可靠度在水工结构设计中的应用
}

\author{
史作言 吴小林 唐骁 张帅 \\ 浙江缙云抽水蓄能有限公司 \\ DOI:10.32629/hwr.v3i11.2482
}

[摘 要] 随着社会经济及科技技术的快速发展, 国家及有关部门对各类工程结构设计不稳定因素的评估及预防提出了更高要求, 使得能够综合 考虑各项因素的结构可靠度理论更加广泛地应用在工程设计、施工、管理等环节中。现阶段在结构可靠性计算期间,可利用概率统计理论知识 来描述工程中的失效概率, 如结构外部荷载情况、材料强度与实际承重力等系数。但由于水工结构设计相较于其他工程结构设计而言, 具有复杂 性、特殊性及不稳定性等特征, 需相关工作人员将结构可靠理论与计算方式进行不断的优化及完善, 为提升水工结构设计质量及可行性提供重要 理论依据。本文就基于此, 以水工可靠度设计研究情况与现状为切入点,对结构可靠度在水工结构设计中的计算模型与可靠度分析进行相关论述, 以供参考。

[关键词] 水工结构; 可靠度; 设计方法

传统的水工结构设计方法是安全系数法。这种方法的材料特性和效果 已为设计师所熟悉。然而, 由于设计中没有考虑随机性的概率, 因此安全系 数法是确定性的设计预防措施, 对于材料性质和行为组合的失效概率没有 明确的规定。本文对其进行分析, 以提高水工结构可靠性设计的整体水平。

\section{1 水工结构可靠度设计的重要性}

在水工结构设计过程中, 需对工程结构的稳定性及安全性基于高度重 视。具体而言, 水工结构建设在工程总耗资量中占据着重要地位, 一旦结构 设计出现误差, 不仅会为建设方带来巨大经济损失, 更会威胁到施工及使 用人员的人身安全。因此, 为更好地预测及评估水工结构设计中的不稳定 因素, 设计单位也开始着手于结构可靠度设计方式的开发及应用。从工程 结构施工角度的分析, 影响结构整体稳定性的原因包括荷载力、材料参数、 结构尺寸、边界条件及计算模型等, 需利用结构可靠度计算方式, 将工程不 稳定因素设为随机变量, 以更好地计算出不同因素对工程整体质量的影响 程度, 并为工程结构设计方案的进一步完善及优化提供重要理论依据。

\section{2 水工结构可靠度设计方法}

2. 1 水工结构可靠度理论

水工结构可靠性的理论基础是极限状态设计方法, 它是在原有的安全 系数设计方法的基础上进行的。目前的水工结构可靠度设计方法比较有限, 表现出承受阻力的结构和参数的作用, 通常被视为随机变量。在水工结构 可靠性设计中, 正常情况下, 极限状态由极限状态方程的效应和阻力组成,

率的计算依据。需要注意的是, 若是地下水位处于试验段以上, 可将地下水 位线作为压力起算零线, 当孔口存在涌水段时, 应将涌水压力水柱高计入 到起算零线内。

\subsection{3固结灌浆}

在本工程中, 固结灌浆采用的是自下向上、孔内循环的灌浆工艺, 以孔 序和排序为依据进行分序灌注。为避免固结灌浆引起基岩或是混凝土抬动 破坏, 应在灌浆时, 做好抬动变形观测。需要特别注意的是, 单元灌浆区域 内同时进行的钻孔冲洗、压水试验和灌浆的孔数最多不得超过 3 个。施工 中, 应当使灌浆压力尽快达到设计值, 对于注入率较大的孔段, 可以采用逐 级分段的方法进行升压。在灌浆升压的过程中, 必须严格按照规范允许的 变形值对抬动进行控制, 如果变形值接近允许值, 则应停止升压, 当升压灌 浆后的变形值上升速度过快时, 应及时恢复至升压前的压力进行灌注施工。 对串通孔进行灌浆时, 应当对灌注压力进行分别控制, 并加强抬动监测。

3 结论
以此来描述极限状态方程为 $Z=g(R, S)=R-S$ 。 然而, 根据概率论, 水工结构可 靠性设计理论分为 I, II, III三个层次。I级是半概率半经验方法, 结构安全 性的影响因素主要包括材料的强度和载荷, 根据实际设计经验引入经验系 数。该方法无法进行可靠概率计算。水准 II 与概率设计方法相似。水工作 用效应 $\mathrm{S}$ 和结构抗力 $\mathrm{S}$ 为随机变量。根据预先设定的概率分布来估计概率分 布。然后使用标准差和均值统计参数或表达式来计算线性规划和处理。III 级全概率法, 是一种基于所有随机变量联合分布的概率方法, 可简化复杂 问题, 但在水工结构设计中很少使用。目前, 在水工结构可靠度设计方法中, II 级概率的近似设计方法应用最为广泛。

2.2 分项系数极限状态表达式

目前的水工结构可靠性设计中, 子系数极限状态表达方法得到了广泛 的应用。在这种方法中, 部分作用系数 $\mathrm{r}$ 和材料属性 $\mathrm{y}$ 的部分系数的物理概 念应该是清楚的, 以便可以有效地反映可能的不确定性。这两个子因素可 能包含超载和退化等物理概念, 但与结构安全的关系较小。根据只作用于 变异性的子系数的作用, 为了确定材料属性的子系数y, 可以由材料试样的 变异性来确定。在水工结构的可靠性设计中, 系数 $r$ 主要表示各种结构抗力 的不确定性, 以及材料性能的子因素, 而不考虑其他因素。比如几何尺寸的 不确定性, 试样的电阻可以转换成元件的电阻不确定度。

\section{3 水工结构可靠度设计方法应用中的障碍}

3. 1 变量不确定

总而言之, 通过对灌浆技术的学习推广, 能够使施工人员对灌浆过程 的控制要点有所了解和掌握, 从而提高灌浆质量, 防止水利水电工程渗漏 情况的发生。为最大限度地发挥出灌浆的防渗漏效果, 要做好质量检查工 作, 只有这样, 才能使灌浆质量得到有效保障。在未来一段时期, 应当加大 对灌浆施工技术的研究力度, 除对现有的一些灌浆工艺进行改进和完善之 外, 还应开发一些新的灌浆技术, 从而更好地为水利水电工程服务, 这对于 促进我国水利事业的发展具有重要的现实意义。

\section{[参考文献]}

[1]高歌.解析在水利水电建筑工程中的基础灌浆施工技术 [J].建材与 装饰,2019(8):90-92.

[2] 魏崧, 何海博.高原地区水利水电工程施工中高压喷射灌浆技术的 应用[J].工程建设与设计,2018(11):165-170.

[3]王建博, 李寒, 杨海荃等. 探讨水利水电工程钻探与灌浆技术 [J].建 材与装饰,2018(38):57. 